\title{
Absolute Solution for Waste Water: Dynamic Nano Channels Processes
}

\author{
Rémi Ernest Lebrun \\ Université du Québec à Trois-Rivières \\ Canada
}

\section{Introduction}

The new concept, which will be discussed in this chapter emerged from the observation that the wastewater contained, in fact, large quantities of elements with high added value, and primarily - water, $\mathrm{H}_{2} \mathrm{O}$. Then the problem to be solved is to sort these elements by using clean technologies that we draw from the whole set of the unit operations of Chemical Engineering. The possibilities offered by flourishing nanotechnologies are tremendous for the characterization of aqueous solutions and for the development of new processes as well. In fact, there is a wide variety of problems. In the $60 \mathrm{~s}$, the idea that nature was capable, if helped a little, to treat all wastewater was widespread because it was considered that the amounts released were small in comparison to the flow of the rivers and the vastness of the seas and oceans. The brutal fact that the vastness is only relative, came from $\mathrm{CO}_{2}$ emissions, reducing the oxygen available and the recent invasion of oil into the Gulf of Mexico that affects shores, the sea bottom and intermediate layers and this, in a large volume. In the past and more recently, the choice was made at large scale to collect and mix the wastewater for a global treatment, usually, municipal, which includes industrial, domestic and medical wastewater. In the context of sustainable development, attitudes change, the selective collection is allowable. But we must go further, much further, recognizing the presence of different resources in each type of waste water and therefore to extract them as much as possible at source, or reuse them on site or to market them after being given an economical value. Nanotechnology can perform these upgrades. Intensive processes allow to perform these small-scale operations at the site of production, reducing the mixing and transport.

In this chapter we will relate progress made over the last 50 years, whether scientific, technological, sociological, ecological, emphasizing nanoscience and miniaturization aspects as well as the integration of expertise in the process management. We will expose specific cases, chosen as the most demonstrative of those we treated, for example:

- treatment of contaminated soil after a burial or a discharge, deliberate or not, of pollutants;

- treatment of municipal wastewater resulting from the collection of releases that uses water as a transport vector,

- $\quad$ regeneration of glycols in airports depending on weather conditions and others;

- $\quad$ reuse of brines for dyeing textile fibers;

- the transfer of copper removed during the etching of printed circuits to the plating of new plates. 
We will present the multidisciplinary theoretical reflections that converge and we will develop a mathematical model describing the phenomenological behavior of aqueous solutions at a nanometer scale that interact with materials constituting the geometric boundaries of the pores. We will describe the experimental methods we have adapted to each case and the tools used in the laboratory and at the pilot scale. We will explain the appropriateness of applying simultaneously exergy analysis and economic analysis as a tool for decision support in the short, medium and long term. The main results will be highlighted and will demonstrate a great potential, offering insight into creative and efficient solutions for the near future. In a context of population and consumption growth, natural resources can no longer be considered inexhaustible. The new resources are those made by humans then discarded after use. They are found largely in waste water and thus in close proximity to areas of consumption.

\section{Fundamental aspects}

\subsection{Phenomenological aspects and modelling}

In the late 50s, after the Second World War, in front of the Gibbs adsorption equation (Gibbs, 1928), exhibited in a corridor at UCLA (University of California at Los Angeles), S. Sourirajan had a luminous interpretation (Sourirajan \& Matsuura, 1985) that led to the development of the first reverse osmosis asymmetric membranes made of cellulose acetate for the desalination of seawater on an industrial scale, but especially to the birth of a new science of flow separation in nanoscale spaces as a result of many interactions between the molecules involved.

$$
\Gamma=-\left(\frac{1}{R T}\right)\left(\frac{\partial \gamma}{\partial \ln (a)}\right)_{T, A}
$$

$A$ : Surface area involved in adsorption $\left(\mathrm{m}^{2}\right)$

$a$ : Activity of solute $\left(\mathrm{mol} \mathrm{m}^{-3}\right)$

$R$ : Gaz constant $\left(\mathrm{J} \mathrm{K}^{-1}\right)$

$T$ : Temperature of the solution $(\mathrm{K})$

$\Gamma$ : Gibbs surface excess of solute $\left(\mathrm{mol} \mathrm{m}^{-2}\right)$

$\gamma$ : Interfacial tension at the air-solution interface $\left(\mathrm{N} \mathrm{m}^{-1}\right)$

It was not until the 2000s and the availability of fast and powerful computers for us to find that the work of Jungwirth (Vrbka et al., 2004) in molecular simulation in nanometer space was, unwittingly, in line with the Sourirajan's interpretation of the Gibbs adsorption equation. The following figure describes perfectly what is considered a crucial step in fluid dynamics in nano-spaces and called by some nanofluidic, which will create a vast field of investigation and discovery in the area of waste water which then become new resources.

Replace the air-salt water interface by pore-salt water interface having the same properties as the air-solution interface allows to rearrange the molecules with a very fast kinetics causing the separation of the solvent in a layer of nanometer range. Moreover, all these models predict an increase in surface acidity and an increase of basicity in the middle. However, during operations to pre-concentration of the sap in Quebec and across the northeastern North America, tens of thousands of maple producers have all found that the reverse osmosis produced permeate was acid when water collected from maple trees was not (Allard, 1998) that we also confirmed in experimental studies on the subject. Recently, 


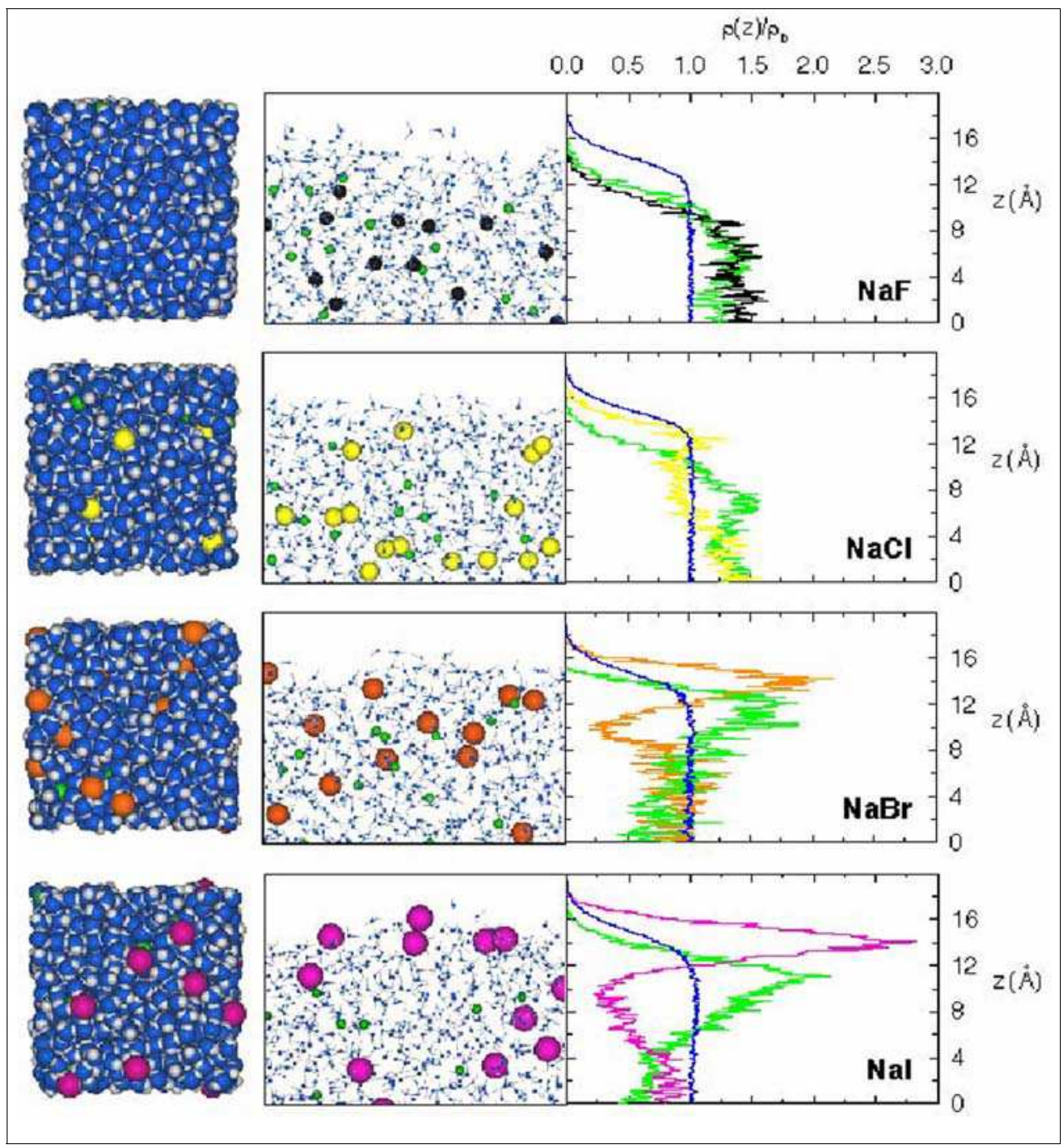

Fig. 1. Left and middle columns: top and side views of snapshots of solution/air interfaces from MD simulations of 1.2 M sodium halide solutions. Right: corresponding number density profiles. Coloring scheme: water oxygen, blue; water hydrogen, gray; sodium ions, green; chloride ions, yellow; bromide ions, orange; iodide ions, magenta. (Vrbka et al., 2004) the Nobel Price has been given to Peter Agre and Roderick MacKinnon (Agre \& MacKinnon, 2003) for their work on the aquaporin channel and the transport of water and ions through the bilipidic membrane cell. This discovery connected in relation with the models, shown before, represent a new approach at the nanoscale to open a great field of research.

On the other hand, always in the late 50s, at the University of Wisconsin, B. Bird clearly defines the concentrations, velocities and fluxes for solutions in motion (Bird et al., 2002). This approach, using the relative velocities of solute and solvent compared to the average 
velocity of the solution, enables him to express the molar flux of solute compared to the molar average velocity of the solution according to the molar concentration gradient and thus, to give Fick's law its true meaning and render it all the necessary rigor. The differential equations of momentum, heat and mass are expressed in terms of a balance on a volume element.

In 1999, we have shown that all these approaches remained fully valid at the nanoscale and that was enough to express different fluid properties and pore geometry to obtain an excellent fit between the predictions of model obtained and the experimental data. We have advanced the concept of dynamic permeability and interpreted from experimental data at very low pressure drop. The water behaves like a Bingham fluid as it flows in nanoscale spaces, highlighting the interactions between molecules.

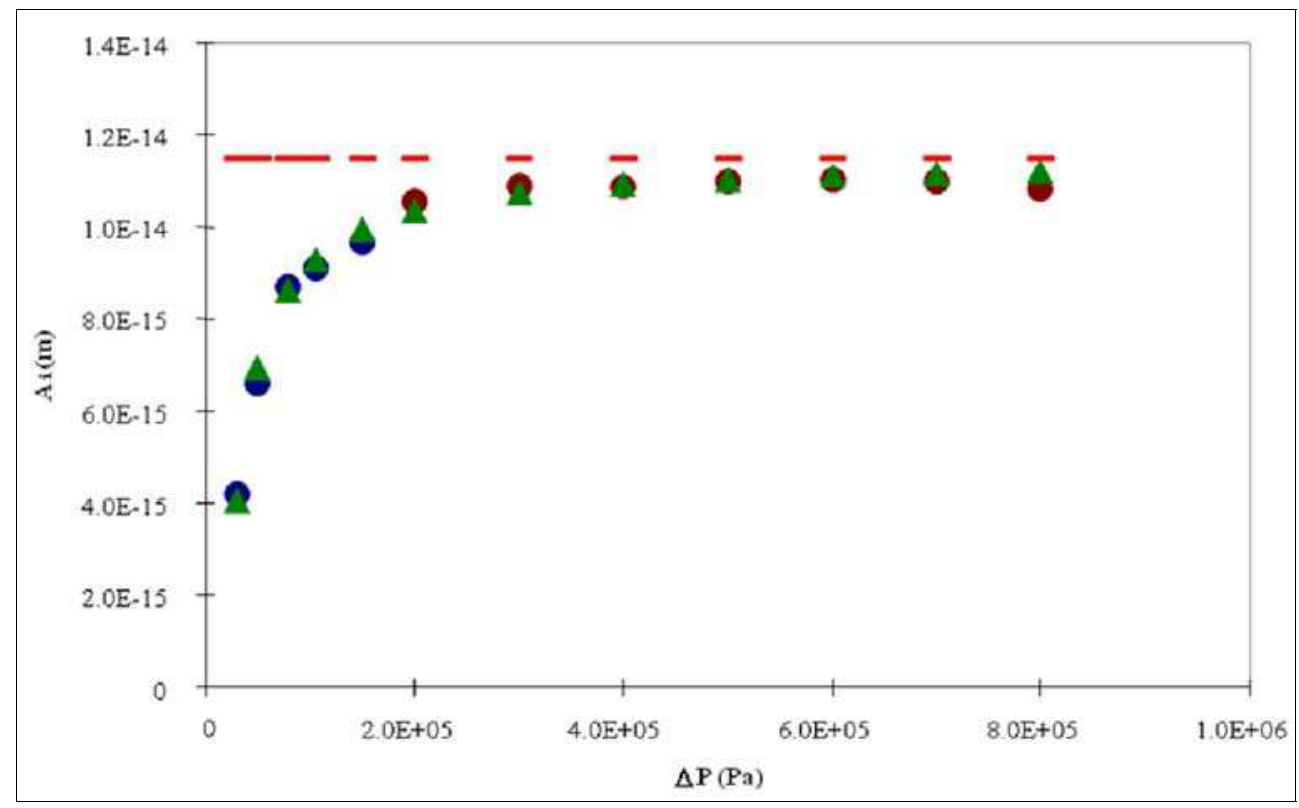

Fig. 2. Permeability of pure water at $25^{\circ} \mathrm{C}$ : comparison of Bingham and Poiseuille models with experimental data in hyperfiltration.

We have defined the dynamic permeability Aid, by analyzing the asymptotic limits of phenomenological equations of transport in a nano filtration module as

$$
\begin{gathered}
Q_{p}=\frac{A_{i d} S_{m}}{\mu}\left[\Delta P_{a}-\left(\Pi\left(X_{m}\right)-\Pi(X)\right)\right] \\
\Delta P_{a}=\Delta P_{m}-\left(\Pi(X)-\Pi\left(X_{p}\right)\right) \\
Q_{p}=\frac{A_{i d} S_{m} \Delta P_{a}}{\mu} \quad \text { when } \quad X_{m} \rightarrow X
\end{gathered}
$$


$A_{i d}:$ Dynamic permeability $(\mathrm{m})$

$Q_{p}$ : Permeate flow rate $\left(\mathrm{m}^{3} \mathrm{~s}^{-1}\right)$

$S_{m}:$ Membrane surface $\left(\mathrm{m}^{2}\right)$

$X$ : Molar fraction of the bulk solution in the membrane module (-)

$X_{m}$ : Molar fraction in the boundary layer at the membrane surface (-)

$X_{p}$ : Molar fraction in the permeate (-)

$\Delta P_{a}:$ Apparent differential pressure $(\mathrm{Pa})$

$\Delta P_{\text {eff }}$ : Effective differential pressure $(\mathrm{Pa})$

$\Pi(X)$ : Osmotic pressure at the molar fraction $X(\mathrm{~Pa})$

$\Pi\left(X_{m}\right)$ : Osmotic pressure at the molar fraction $X_{m}(\mathrm{~Pa})$

$\Pi\left(X_{p}\right)$ : Osmotic pressure at the molar fraction $X_{p}(\mathrm{~Pa})$

$\mu$ : Solution viscosity of the solution in the membrane pore (Pa s)

We also showed that the pore size consisting of material such as polyamide, could shrink depending on temperature and this, in a reversible manner. The geometry of the pores can also vary depending on the $\mathrm{pH}$ or the concentration in solute of flow solutions. Other similar effects, due to the presence of an electric field, have also been shown.

We modeled the coupling of mass transport in the boundary concentration layer and in the pores using the double distribution of pores (Sourirajan \& Matsuura, 1985). Then, we described each of these phenomena according to the Fick's law of diffusion as expressed by Bird (Bird et al., 2002), to find different expressions in the boundary concentration layer.

$$
J_{A}^{*}=-D_{A B} \nabla\left(c X_{A}\right)
$$

$c$ : Molar concentration of the solution $\left(\mathrm{mol} \mathrm{m}^{-3}\right)$

$D_{A B}$ : Diffusion coefficient $\left(\mathrm{m}^{2} \mathrm{~s}^{-1}\right)$

$J_{A}^{*}$ : Solute molar flux relatively to average molar velocity of the solution $\left(\mathrm{mol} \mathrm{m}^{-2} \mathrm{~s}^{-1}\right)$

In this case, the flow rate of fluid or backdiffusion flow rate is proportional to the concentration gradient (driving force). The coefficient of proportionality is the diffusion coefficient.

We expressed the flow separation in a pore by an entirely new model.

$$
\nabla\left(c X_{A}\right)=+c \Re_{A B}^{M} J_{A}^{*}
$$

$\mathfrak{R}_{A B}^{M}$ : Diffusion coefficient in the membrane pore $\left(\mathrm{m}^{2} \mathrm{~s}^{-1}\right)$

By integrating this differential equation we have shown the existence of a minimum and maximum separation (and not asymptotic as in other models). This finding represents a situation with no interaction. If we insert into the model the affinities between solventsolute-porous material, the obtained leverage will depend on the relative dimensions between the different components.

$$
\begin{array}{r}
\frac{f_{1}^{\prime}-f^{\prime}}{f_{1}^{\prime}-f_{0}^{\prime}}=\exp \left(-\frac{r_{p}^{2} \Delta P_{M}}{8 \mu^{M} \Re_{A B}^{M}}\right) \\
f^{\prime} \text { : Intrinsic separation factor define by } f^{\prime}=\left(\frac{X_{m}=X_{p}}{X_{m}}\right)(-)
\end{array}
$$


$f_{0}^{\prime}$ : Minimum intrinsic separation factor (-)

$f_{1}^{\prime}$ : Maximum intrinsic separation factor (-)

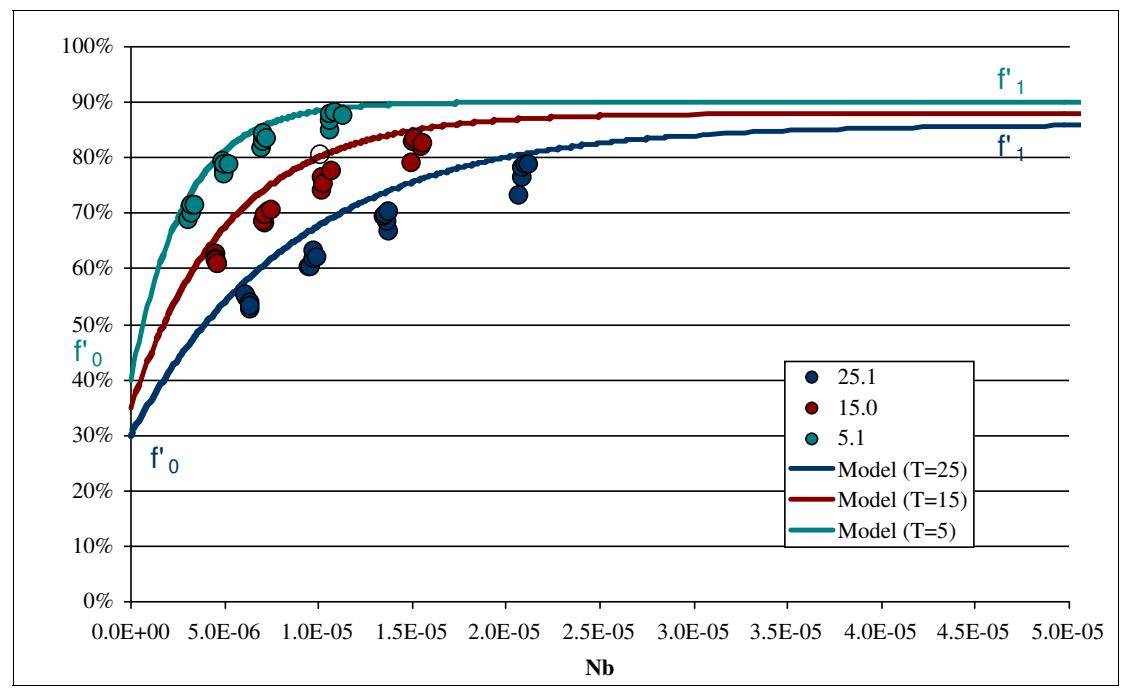

Fig. 3. Experimental data for nanofiltration of DEG in aqueous solution at different temperatures. Adequacy of the model of separation flow in a nanoscale pore.

Related to very important developments made by Sourirajan who expressed the interactions as changes of Gibbs free energy in a micro-canonical ensemble described by the following equations:

$$
\begin{gathered}
\ln \left(\frac{D_{A M}}{K \delta}\right)=\ln \left(C_{N a C l}^{*}\right)+\ln \left(\Delta^{*}\right)+\left(\frac{-\Delta \Delta G}{R T}\right)+\delta^{*} \sum E_{s}+\omega^{*} \sum s^{*} \\
\frac{-\Delta \Delta G}{R T}=\frac{-\left(\Delta G_{I}-\Delta G_{B}\right)}{R T} \\
\Delta G_{I}=\sum \gamma_{I} \text { (structural groups) }+\gamma_{I, 0}
\end{gathered}
$$

With:

$$
\Delta G_{B}=\sum \gamma_{B}(\text { structural groups })+\gamma_{B, 0}
$$

For this purpose these definitions are sufficient. To know more refer to Sourirajan (Sourirajan \& Matsuura, 1985 p.131)

From these different groups, it is possible to define the properties of a material, the pore size to obtain the desired separation for a given solution.

This set of models allowed us to understand and express the geometric variations of nanoscale spaces between the polymer chains according to the presence of ionic species. The 
figure below shows that the adequacy between model and experiments, clearly expresses the phenomenological behavior of molecules (solvent, solute, pore material) at the nanoscale.

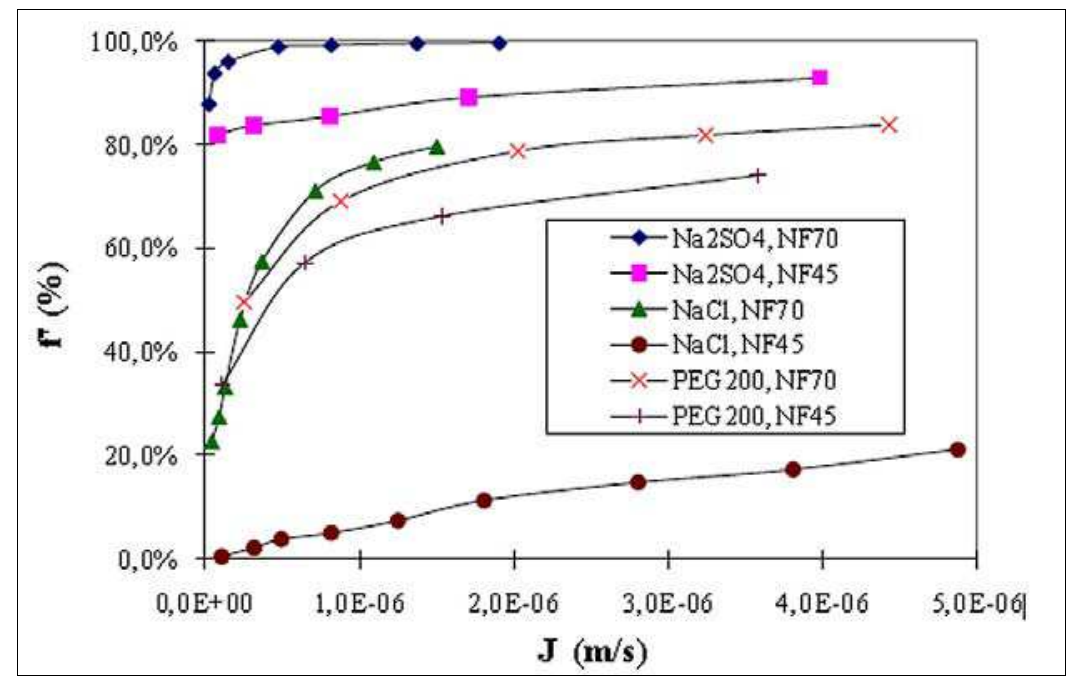

Fig. 4. Experimental data for nanofiltration (NF70 and NF45) for solutions of PEG, $\mathrm{Na}_{2} \mathrm{SO}_{4}$, $\mathrm{NaCl}$ : Modeling maximum and minimum separation factors based on permeation flux.

These new insights have enabled the development of new processes for treating wastewater. After defining the desired permeate and concentrate flows, from a wastewater properly characterized, the choice of polymer and pore size provides a synergistic effect. On this basis the process design is then possible and the optimization is based on industrial and economic constraints.

\subsection{Analysis tools for the design optimization}

Modeling and understanding of transport phenomena in nanoscale pores help design the processes required to sort the elements present in wastewater and choose to isolate them, group them or turn them into new elements. The objective function must be defined in terms of possible added value of the various flows that can be created by minimizing releases to the environment in relation to expressed needs. A scientific tool for analyzing the performance of the new process is the exergy analysis. This analysis, coupled with an economic analysis, allows to know the degree of valorization over the maximum possible in the context of wastewater available and immediate needs.

Here is an example of exergy analysis of a method for wastewater valorization: The simplest configuration is illustrated in the figure below (one-stage continuous process). Several parameters are defined as follows:

- $\quad$ Average operating pressure

$$
P=\left(\frac{P_{m e}+P_{m s}}{2}\right)
$$




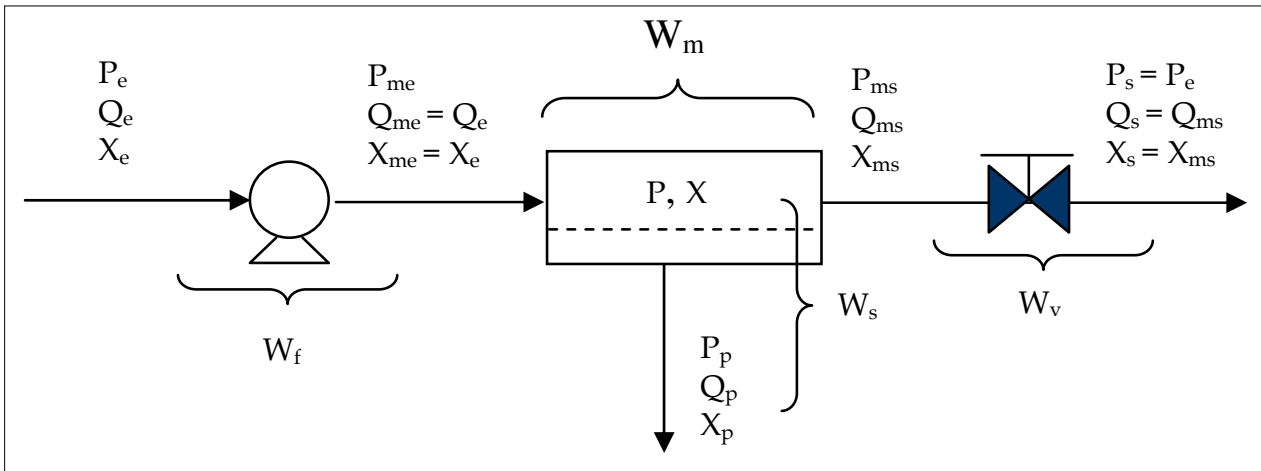

Fig. 5. Systemic diagram of a simple process.

- Average recirculation flow rate in the module

$$
Q=\left(\frac{Q_{m e}+Q_{m s}}{2}\right)
$$

- Average molar fraction of the solute in the module

$$
X=\frac{X_{m s}-X_{m e}}{\ln \left(\frac{X_{m s}}{X_{m e}}\right)}
$$

- $\quad$ Osmotic pressure gradient

$$
\Delta \pi=\pi(X)-\pi\left(X_{p}\right)
$$

- Apparent transmembrane pressure

$$
\Delta P_{a}=P-P_{p}
$$

- Effective transmembrane pressure

$$
\Delta P_{e f f}=\Delta P_{a}-\Delta \pi
$$

Ideal system: minimum work of separation

The separation of a homogeneous binary mixture of different compositions needs certain devices that consume energy in the form of work and/or heat. The minimum work to make a separation, whatever the method used, is calculated by considering a reversible and isothermal separation. This minimum work of separation depends only on the composition, temperature and pressure of the initial mixture and different final fractions. For a separation of a homogeneous mixture into pure products at constant temperature, the minimum work to provide can be calculated by the formula:

$$
W_{\min }=-N R T \sum_{j} X_{j} \ln \left(\gamma_{j} X_{j}\right)
$$


where $W_{\min }$ is the minimum work required for separating of the mixture flow $(\mathrm{W})$;

$\mathrm{N}$ is the molar flow of the mixture flow $\left(\mathrm{mol} \mathrm{s}^{-1}\right)$;

$\mathrm{R}$ is the constant of ideal gases $\left(\mathrm{J} \mathrm{mol}^{-1} \mathrm{~K}^{-1}\right)$;

$\mathrm{T}$ is the temperature of the system and its environment that is kept constant $(\mathrm{K})$;

$X_{j}$ is the mole fraction of component $j$ in the initial mixture;

$\gamma_{\mathrm{j}}$ is the activity coefficient of component $\mathrm{j}$ in the initial mixture.

Where products are not pure, the minimum energy consumption can be calculated by subtracting from the equation (16), the minimum work to transform impure products to pure products. In the case where the solute concentration is low, the activity coefficients are taken equal to 1 , and that to simplify calculations. If we use the same symbols shown in Figure 5, we obtain the following equation to calculate the minimum work to separate a feed stream $\left(\mathrm{N}_{\mathrm{e}}\right)$ in a permeate flow $\left(\mathrm{N}_{\mathrm{p}}\right)$ and a concentrate stream $\left(\mathrm{N}_{\mathrm{s}}\right)$ :

$$
\begin{aligned}
W_{\min }= & -R T\left\{N_{e}\left[X_{e} \ln X_{e}+\left(1-X_{e}\right) \ln \left(1-X_{e}\right)\right]\right. \\
& -N_{p}\left[X_{p} \ln X_{p}+\left(1-X_{p}\right) \ln \left(1-X_{p}\right)\right] \\
& \left.-N_{s}\left[X_{s} \ln X_{s}+\left(1-X_{s}\right) \ln \left(1-X_{s}\right)\right]\right\}
\end{aligned}
$$

where $\mathrm{N}_{\mathrm{e}}$ is the molar flow of the input solution ( $\left.\mathrm{mol} \mathrm{s}^{-1}\right)$;

$\mathrm{N}_{\mathrm{p}}$ is the molar flow rate of permeate $\left(\mathrm{mol} \mathrm{s}^{-1}\right)$;

$\mathrm{N}_{\mathrm{s}}$ is the molar flow of concentrate $\left(\mathrm{mol} \mathrm{s}^{-1}\right)$.

A method for doing the separation of a mixture where there are changes in temperature, pressure and concentration, the exergy of a fluid stream can be presented as the sum of the thermal exergy $E_{x}{ }^{T}$, the mechanical exergy $E_{x}{ }^{P}$ and chemical exergy $E_{x} C$ [equation 18-21]:

$$
E_{X}=E_{X}^{T}+E_{X}^{P}+E_{X}^{C}(
$$

where thermal exergy

$$
E_{X}^{T}=Q\left[C_{P}\left(T-T_{0}\right)-c_{p} \ln \left(\frac{T}{T_{0}}\right)\right]
$$

mechanical exergy

$$
E_{X}^{P}=Q\left[\left(P-P_{0}\right)\right]
$$

chemical exergy

$$
E_{X}^{C}=-N R T_{0} \sum\left[e_{i}-X_{i} \ln \left(\gamma_{i} X_{i}\right)\right]
$$

$E_{x}$ is the flow exergy (W)

$\mathrm{c}_{\mathrm{p}}$ is the specific heat of the solution $\left(\mathrm{J} \mathrm{m}^{3} \mathrm{~K}^{-1}\right)$

$e_{i}$ is the exergy of pure product $i$.

$\mathrm{T}_{\mathrm{o}}, \mathrm{P}_{\mathrm{o}}$ are the temperature and pressure of the reference state.

For the process (fig. 5) the following hypothesis have been done:

1. $\mathrm{T}_{0}$, the operating temperature is constant

2. The binary solution is homogenous and the activity coefficients are fixed to 1 ;

3. Pressures are $\mathrm{P}_{\mathrm{e}}=\mathrm{P}_{\mathrm{p}}=\mathrm{P}_{\mathrm{s}}=\mathrm{P}_{\text {atm; }}$;

4. The pump efficiency is equal to $100 \%$.

The exergy balance on this process is defined as follow:

$$
W_{f}=W_{\min }+T_{0} \Delta S
$$


Where $\mathrm{W}_{\min }$ et $\mathrm{W}_{\mathrm{f}}$ are calculated by equations (17) et (22) and $\Delta \mathrm{S}$ is the entropy generation. Equation (22) appears as:

$$
\begin{aligned}
& \mathrm{Q}_{\mathrm{p}}\left(\frac{\mathrm{P}_{\mathrm{me}}+\mathrm{P}_{\mathrm{ms}}}{2}-\mathrm{P}_{\mathrm{p}}\right)+\mathrm{Q}_{\mathrm{ms}}\left(\mathrm{P}_{\mathrm{me}}-\mathrm{P}_{\mathrm{ms}}\right)+\mathrm{Q}_{\mathrm{ms}}\left(\mathrm{P}_{\mathrm{ms}}-\mathrm{P}_{\mathrm{s}}\right)= \\
& \mathrm{W}_{\mathrm{min}}+\mathrm{T}_{0}\left(\Delta \mathrm{S}_{\mathrm{e}-\mathrm{p}}+\Delta \mathrm{S}_{\mathrm{e}-\mathrm{ms}}+\Delta \mathrm{S}_{\mathrm{ms}-\mathrm{s}}\right)
\end{aligned}
$$

Where $\Delta \mathrm{S}_{\mathrm{e}-\mathrm{p}}, \Delta \mathrm{S}_{\mathrm{e}-\mathrm{ms}}$ et $\Delta \mathrm{S}_{\mathrm{ms}-\mathrm{s}}$ are the entropy generations between the referred points of the fig.(1). The exergetic efficiency of such a system can be defined by (Brodyansky et al,1995):

$$
\eta_{e}=\frac{W_{\min }}{W_{f}}
$$

\subsection{Examples of general application}

The following example is generic to show how this tool can be applied: a concentrated solution which, after use, is diluted and contaminated by other elements.

Considered as waste before government standards, the wastewater was discharged into the environment. To continue production operations, the pure products (solid) were purchased and then mixed with pure water, purchased or produced from a local source, to obtain the desired concentrated solution. This solution was heated to the operating temperature to be used in the production process. However, exergy analysis shows that there is energy generation when mixing pure products and pure water: energy, which usually is not recovered. If we consider that contamination may be removed, we obtain a dilute solution of good quality. The temperature level is maintained at the lowest energy cost since the solution is recycled. From a viewpoint of exergy analysis, the best performance is to concentrate the resulting solution to obtain the desired solution. The same analysis can compare various processes to determine for each process the most efficient operating range. It also helps to optimize each process on the basis of thermodynamic irreversibility.

The wastewater can be classified according to the exergy analysis. Leachate contaminated soil or municipal wastewater, generated naturally or by simple collection, represent a category.

The primary interest is often to treat this wastewater for discharge into the receiving environment based on standards. There are still few places where we seek to enhance their content. However, domestic wastewater is treated and reused in the space station. Indeed, water is prohibitive, reuse water becomes clear. Whole buildings in Japan treat wastewater generated internally, based on the idea of Yamamoto (Choi et al., 2006), and a single booster is used, which allowed for significant space savings by reducing the pipes.

A large category includes wastewater at the exit of processes that have a greater level of exergy that water supply. This exergy is thermal exergy (hot water discharge), or mechanical exergy (high pressure discharge) or chemical exergy (water of high purity). Another category includes wastewater containing chemicals used in excess in the production process, which are rejected because in the presence of contaminants. Presumably another category contents washing cars or textiles with the use of detergents and high temperatures, cleaning with acids or bases that are found in pulp and paper industry in the plating. The solution in this case, was to neutralize the waste to meet environmental standards and to purchase acid and basic production needs. However, these products 
represent costs, risks (storage and transport) and standards for salts are closing more and more. This situation prevents the neutralization that generates salts.

From another point of view, the human body can be perceived as a real chemical engineering plant. It is an excellent example of exergy efficiency. The introduction of drugs, often in excess, in the entire body is an example of exergy losses. Moreover, the presence of endocrine precursors (from these drugs) in wastewater is now recognized as a serious public health problem. Fortunately more and more controlled drugs diffusion and the possibility of detecting the target to be treated are promising solutions.

\subsection{Characterization of nanoscale pores}

We have seen that the pore size and surface forces of the material forming these pores are of crucial importance to minimize energy costs. An essential tool for characterizing the pore size is the analysis of structures by near-field scanning microscopy. The image analysis of generated images allow quantification of the size and size distribution of pores and their surface distribution. The great advantage of this method is that it is not destructive and it works in an ambient or controlled atmosphere as well as in liquid medium that can be modified depending of temperature, pressure, $\mathrm{pH}$, salt concentrations, etc.

The following figures, we have realized in the laboratory, illustrate the topology of membranes at different scales. The depth of 3-D images is indicated. Areas of $2 \mu \mathrm{m}$ each side up to areas of $10 \mathrm{~nm}$ each side are presented below. Different materials have been studied (ceramics, polymers). Figure 8 shows the cyclodextrins of $100 \mathrm{~nm}$, retained by the ceramic membrane with pores of about $20 \mathrm{~nm}$, during a permeation of an aqueous solution of 100 ppm of cyclodextrins. Figure 9 presents a surface modification of the ceramic membrane with an polyvinil oxide solution. Figure 10 shows a detail of the morphology of the new surface. These images show the beginning of a characterization of dynamic pores.

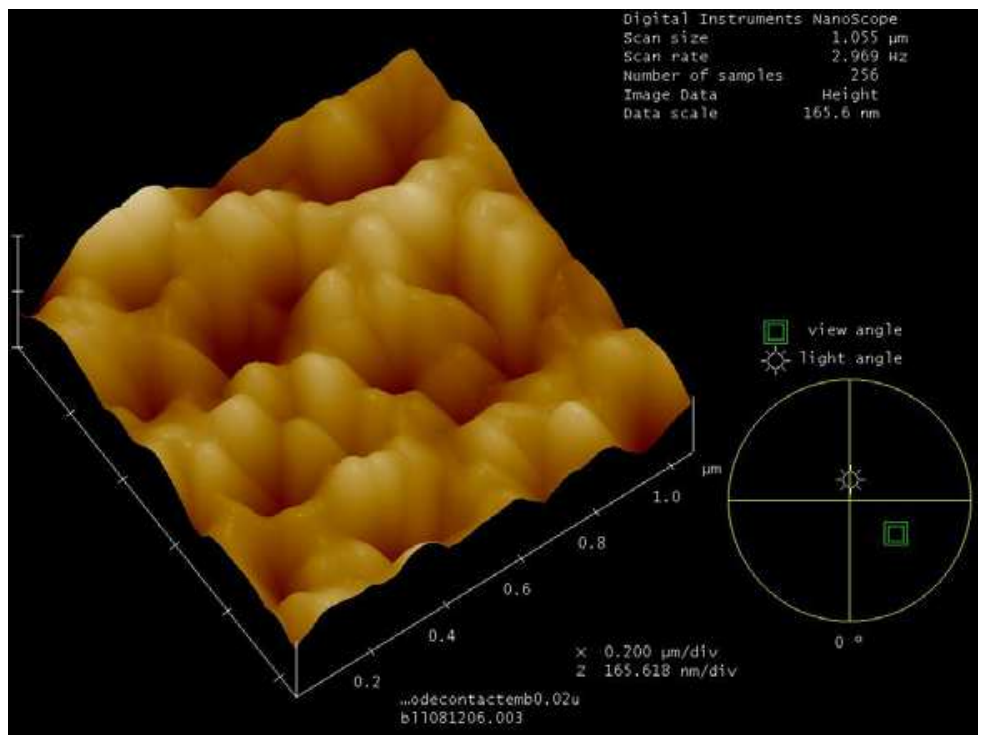

Fig. 6. Ceramic membrane $D_{p}=20 \mathrm{~nm}$. Image Scanning Probe Microscope $1 \times 1 \mu \mathrm{m}$, contact mode, ambient air. 


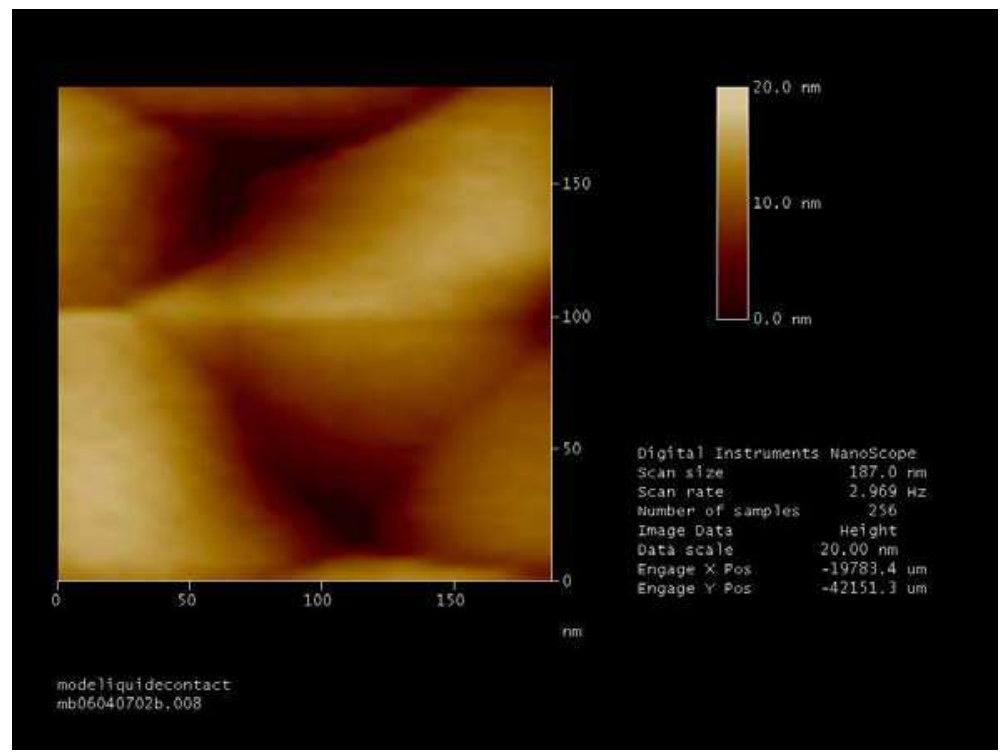

Fig. 7. Ceramic membrane $D_{p}=20 \mathrm{~nm}$. Image Scanning Probe Microscope 200x200 nm, contact mode, ambient air.

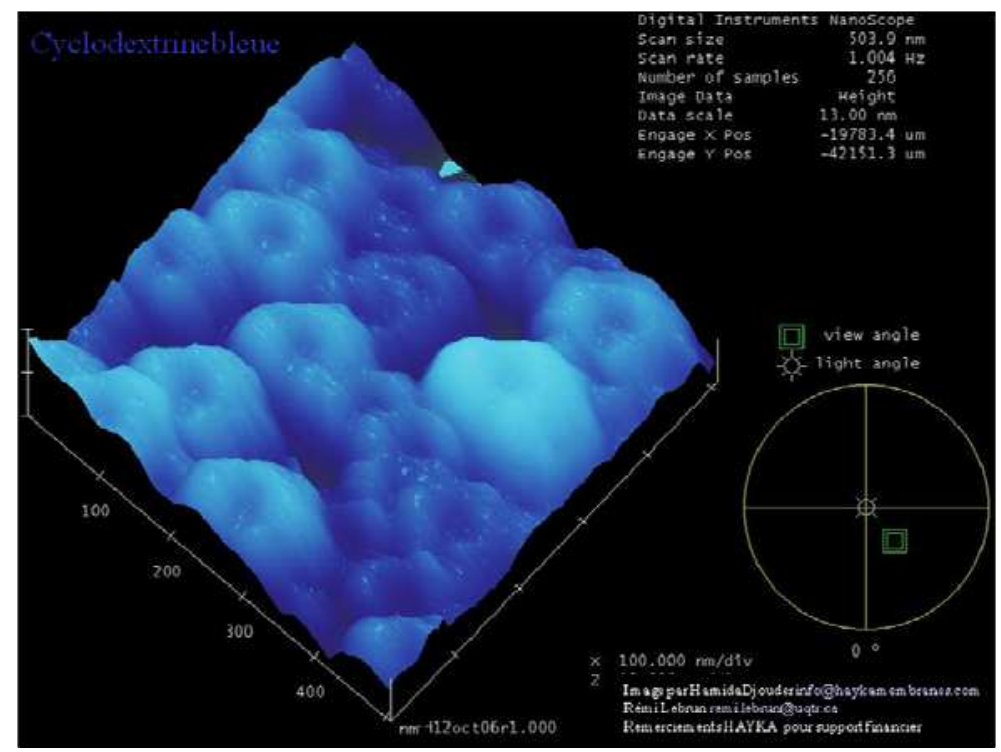

Fig. 8. Blue cyclodextrin on ceramic membrane $D_{p}=20 \mathrm{~nm}$. Image Scanning Probe Microscope 500x500 nm, contact mode, aqueous medium, ambient temperature and pressure. 


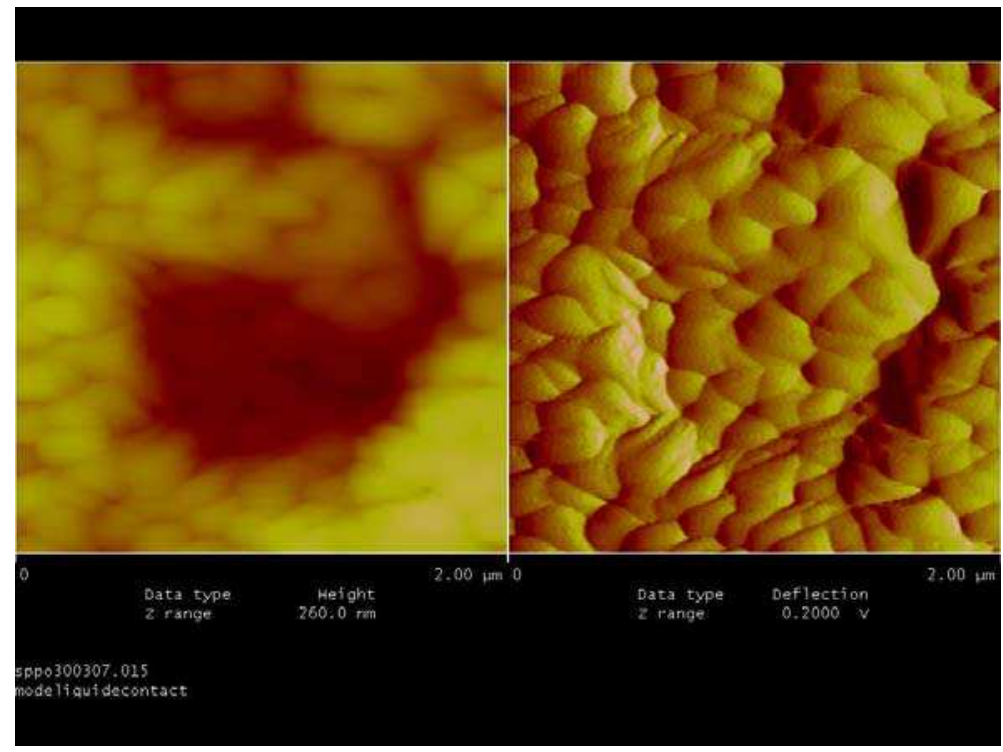

Fig. 9. Surface modification of ceramic membrane $\mathrm{Dp}=20 \mathrm{~nm}$ with sulfonated oxide of polyphenyl. Image Scanning Probe Microscope $2 \times 2 \mu \mathrm{m}$, contact mode, aqueous medium, ambient temperature and pressure.

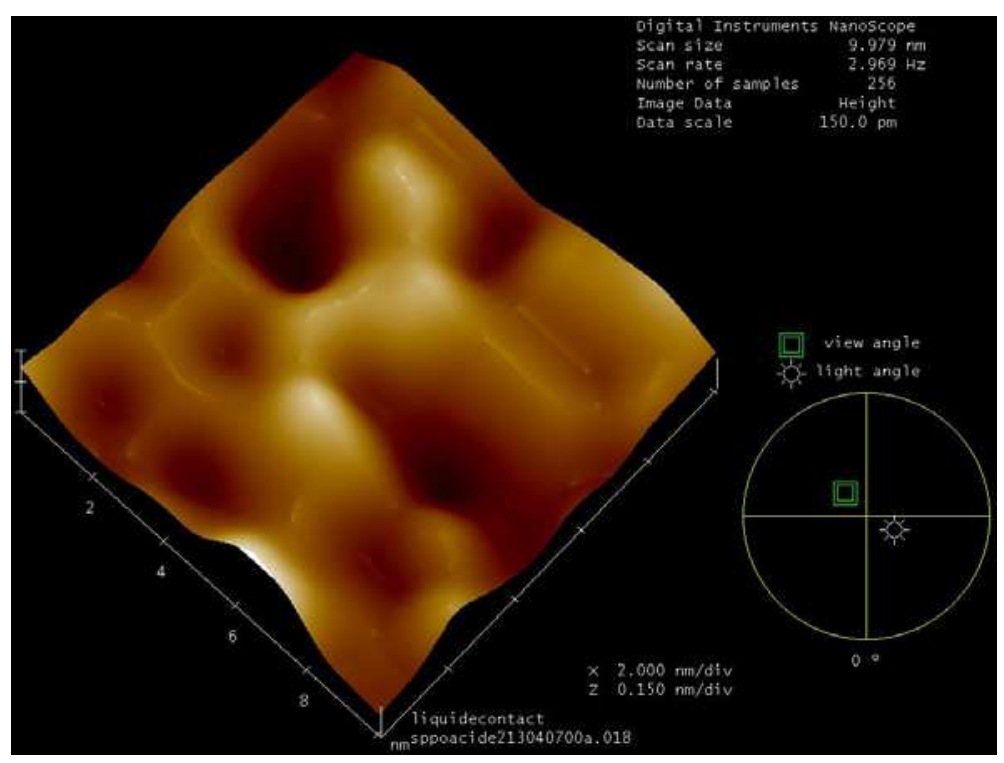

Fig. 10. Surface modification of ceramic membrane $D_{p}=20 \mathrm{~nm}$ with sulfonated oxide of polyphenyl. Image Scanning Probe Microscope 10x10 nm, contact mode, aqueous medium, ambient temperature and pressure. 


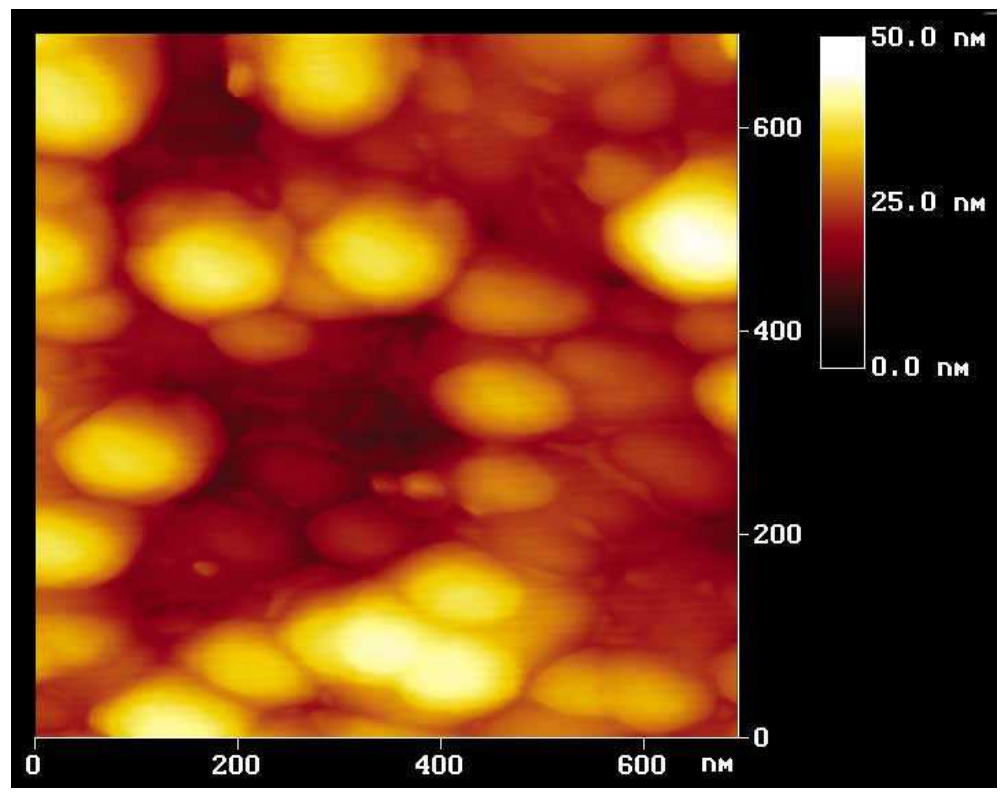

Fig. 11. Cellulose acetate membrane manufactured according to the recipe of the first membranes of Loeb and Sourirajan. Image Scanning Probe Microscope 600x600 nm, contact mode, aqueous medium, ambient temperature and pressure.

In the case of processes based on organized nanoscale pores, two avenues can be considered:

- Minimize losses due to irreversible phenomena

Maintaining the maximum separation of solute compared to the solvent, it is possible to minimize losses by reducing charge losses in a pore or by reducing its length or by providing flared shapes (Sourirajan \& Matsuura, 1985). We can also increase the radius of the pore and maintain the separation. It may be noted that the number of pores increase the exergy efficiency by decreasing the operating pressure and therefore allows to approach the minimum work of separation, provided that it respects the maximum separation, and the minimum pressure corresponding to this maximum separation. By opposite when the separation varies with the pressure, which represents the irreversible thermodynamics, the margin for maneuver is limited. It is the same with the variable temperature, to a lesser extent.

- $\quad$ Make processes more intensive (maximum production with minimal bulk)

If the most important criterion is to have a process as compact as possible, then it is possible to organize the material to increase the number of pores per surface unit and increase the operating conditions (temperature and pressure ). The energy cost of the operation of such a process will then increase and other risks may be associated with this avenue. Often the exergy of the concentrate current will be increased to an unnecessary value which may very often lead to energy loss during the operation.

Processes such as evaporation, vacuum evaporation, multiple effect evaporation, hyperfiltration, nanofiltration, electrodialysis, membrane distillation, etc. Each of these processes can be most efficient for a certain range of concentration and, therefore, a process 
consisting of several of these unit operations may be the most efficient method for a given problem. For cons, the chosen solution may be slightly different because of the availability of equipment and according to economic analysis. Some of these unit operations have marked scale effects, othera as membrane processes are much less sensitive.

\section{Strategy of the process design}

\subsection{Wastewater, its origin: a systemic analysis}

The origin of the wastewater is very important in our conceptual framework. For a long time the grouping of wastewater has been a strategy to benefit from scale effects of treatment processes. Currently, whether municipal or industrial, the selective collection is increasingly applied. The analysis means of wastewater is becoming increasingly sophisticated for a wide variety of molecules and are more accurate but costs remain high.

Our strategy applies to a unit of industrial production (defined as a system situated in an environment with its inputs and outputs). Systemic analysis begins with mass balances and exergy balances (energy, temperature level, air pressure, chemical potential) on each of the currents on the global system and subsystems to explore opportunities to create loops of internal recycling process.

This methodology is based on different principles :

Know the production line, its inputs, its outputs, the present reactions, the necessary energy levels, the separations and mixtures used will help to reduce analysis costs by reducing their frequency and their level of accuracy. A program for analyzing the quality of raw materials and products to help maintain constant operating conditions.

- The mixture of two or more fluid currents or energy must be at the same level of exergy. If one of the currents is below this level its exergy must be increased and this expense should be accounted. This represents an extension of the pinch technology applied in energy saving.

These tools cannot give an objective analysis because they can optimize an existing situation (a process in place) or optimize a newly developed method which is subjected to the method. In no case they cannot directly provide an optimum process. Moreover, the constraints imposed upon the posing of the problem restrict the degrees of freedom of the designer.

An interesting example is the treatment of toxic groundwater resulting from leaching of contaminated soils. Indeed, the fact of using the word "toxic" leads the designer towards what might be considered as a red herring. It must reflect the standards and regulations and optimize a method based on those constraints that apply to the current that must return to the receiving environment and other currents that may be released into the environment. However, if we define the wastewater according to its composition, the elements responsible for the toxicity and ecotoxicity represent a very small amount of dissolved matter (in the order of $10^{-1} \mathrm{~kg} \mathrm{~m}^{-3}$ or $100 \mathrm{ppm}$ ). So we can consider that these waters contain a large amount of very pure water. The proposed method allowed to produce high quality water that could have multiple uses for treated water:

- Flow to the river

- $\quad$ Back to the site for irrigation as leaching water to accelerate soil washing.

- Use as process water for industry

- Use as drinking water 
For other currents there are several possibilities:

- Use of a concentrate as fertilizer

- Use of a produced baking soda

- Using other solids in the manufacturing of concrete

The content of some currents, in very small percentages, is destroyed by an elementary chemical reaction. What is remarkable is that this reaction is not possible when the element is part of the mix. Its separation allowed the reaction without producing pollution.

Other separations were carried out to avoid adverse reactions. A peculiarity of this type of separation in nanoscale pores is that the composition of the concentrate side of the fluid current is always changing, which means that the exergy varies throughout the process. In principle, if separation does not depend on the composition of the fluid, operating conditions must change. Moreover, if the separation depends on the composition, then the pore size should change with changes in concentrations and composition. A simple criterion of optimization is to adjust the pore size and operating conditions to obtain a permeate composition and constant concentration.

\subsection{Designing a sequence of unit operations}

Considering the above principles, based on the analysis of wastewater, it is possible to characterize their content in different groups of particles or molecules. Consider a ground water containing suspended particles, bacteria, hydrocarbons and ions in solutions. For each category it is possible to optimize the pores to make the complete separation of the category. Systematically we can define the system by the following sequence:

$\begin{array}{lll}\text { Input Current } & \text { Unit 01 Concentrate current 01 } & \text { particles } \\ \text { Permeate current 01 } & \text { Unit 02 Concentrate current 02 } & \text { bacteria } \\ \text { Permeate current 02 } & \text { Unit 03 Concentrate current 03 } & \text { hydrocarbon } \\ \text { Permeate current 03 } & \text { Unit 04 Concentrate current 04 } & \text { type I ions = solid } \\ \text { Permeate current 04 } & \text { Unit 05 Concentrate current 05 } & \text { type II ions = solid } \\ \text { Permeate current 05 } & \text { Unit 06 Output current 06 } & \text { water + ions = quality }\end{array}$

Analysis of reuse and of the nature of the valorization of each of the currents.

Concentrate 01:

Most of the particles can be put back on the ground and be washed again by water produced in the current 06 . This surface wash continue thoroughly to accelerate the leaching of this former landfill.

Concentrate 02:

Bacteria with specific properties extracted from groundwater are concentrated and can be a base for supplying a bioreactor.

Concentrate 03:

The hydrocarbons extracted have energy value.

Concentrate 04:

These divalent salts can be separated by selective precipitation and form dry product or be used as additives for different applications.

Concentrate 05:

Other types of monovalent salts can be recovered in the same manner as before.

Process 06: 
This advanced oxidation process allows the destruction of toxic material (eg.: Ammonia nitrogen). This reaction is not possible in the feed water

Energy costs throughout the process are related only:

- to losses in nanoscale pores,

- to pressure levels that are depending on the osmotic pressure difference,

- to pumps and motors performance,

- $\quad$ but independent of temperature level (operating at room temperature).

The charge losses are the same whether the fluid flows through a pipe (macro level) or that flows into microscopic pores (hollow fiber or micropores) or nanoscopic (with few exceptions), provided that the number of pores are enough in comparison to the length of the pores.

$$
\Delta P=\frac{64 \mu(T) Q_{p} L_{T}}{D_{T}^{4}}=\frac{64 \mu(T) Q_{p} L_{P}}{n_{P} D_{P}^{4}}
$$

So there are no limitations due to having a flow in nanoscale pores. The only energy barrier is the exergy differential between currents. This can be translated in terms of osmotic pressure, level of chemical potential, etc. The temperature level can play a role but it is not a necessity. An example of application that illustrates these results is the treatment of wastewater that must be transported from point A to point B in a pipe using pumps. Then we can design a set of organized systems in nanoscale pores that can be installed in seriesparallel in a tree form. If the pore size is smaller than the size of particles or molecules to be separated, then no additional energy is required to effect the separation, provided that one adjusts consequently the number of pores and that the flow is laminar (Equation 25).

Another example allows to choose between two methods depending on the concentration range of wastewater. If we consider a wastewater containing monovalent salts that must be addressed. If the salt concentration is low, then the hyperfiltration is a common solution. If the salt concentration is high, the electrodialysis is a popular choice. The fundamental difference between the two processes is the transport of molecules. In the first one it is the water that flows through the pores; in the other it is the salt ions that are the subject of transportation. When the concentration is low, the osmotic pressure is low and the operation pressure (which is the driving force for hyperfiltration) is common, on the other side to migrate the salt ions under a difference of electric potential (which is the force motive for the electrodialysis) power consumption is important. When the concentration increases it is the opposite. This leads us to design a sequential process consisting of hyperfiltration then electrodialysis. This configuration provides synergy and reduces the losses of exergy from a process that would do the same separation whatsoever hyperfiltration.

\section{Case studies}

Over the past 25 years we have had the opportunity to work on many cases of wastewater treatment in Canada. We will present them a summarily based on their category and not in chronological order. In most cases, the request was to treat the wastewater to allow its release into the environment. In all cases it was possible to provide sustainable solutions for all or part of the fluid streams. For this we have designed, fabricated and operated pilot units to demonstrate the feasibility of the proposed treatment. We have also, using a software, designed and simulated processes scaling. At the laboratory scale, were used to 
test units used at UCLA (Sourirajan \& Matsuura, 1985). We also designed and produced pioneering experimental assemblies to characterize both commercial membranes and those manufactured in the laboratory. We were able to transfer the methods of characterization, from laboratory to pilot scale, which also allowed us to transfer the methods enabling changes of structure and membranes surface available on the market. We could adjust the size of pores and surface affinities to the problem studied.

We will present summaries of these experiments using the categories presented in Chapter 2. The important progress made in the last 50 years, both in research and the industry have made available on the market the membrane modules with a variety of materials and structures (Drioli E. \& Giorno, L, 2010). The surface/volume ratio was significantly reduced to allow achievement of intensive processes. Permeability and separation also increased resulting in improved process efficiency. Costs, usually compared with the standard $\$ / \mathrm{m}^{2}$ of membrane, were greatly reduced from $\$ 100$ to $\$ 25 / \mathrm{m}^{2}$ of membrane. But because performance per $\mathrm{m} 2$ of membrane surface increased, costs per $\mathrm{m}^{3}$ of treated wastewater decreased. In addition, improving the treatment strategy, as we have seen above, greatly reduced operating costs.

\subsection{Groundwater from old municipal landfills}

In this case, the wastewater becomes an obligation because the stormwater becomes charged with toxic elements while seeping in the soil then the toxic groundwater flows off-site to discharge into surrounding watercourses. This water cannot be recovered and mixed with municipal wastewater because it does not meet standards. Many characterization studies were conducted over the past 25 years, which provide familiarity with their composition and geographical distribution.

The first approach, based on our systematic approach has been to separate the collection of oily water, for which treatment method will be developed, from the groundwater. It is obvious that the mixture of these two waters is probably the worst operation to be performed. Then, analysis of groundwater revealed that few elements, in mass, contaminate groundwater. Suspended solids, mainly soil, small amounts of bacteria, some traces of hydrocarbons and dissolved salts whose main ecotoxicity source is known to be ammonia nitrogen.

Our strategy was to extract suspended particles and get rid of harmful elements still present before being used for landscaping of the site. The leachate will then be reprocessed by the main system. Bacteria in groundwater form a consortium developed at low temperature under anaerobic conditions. Extract and concentrate them is on one hand valorize them, and, secondly, sterilize water to be treated which for the sequence of unit operations downstream, allows to avoid the formation of biofilm representing a limiting factor for system operation. In these conditions it is easier to design a appropriate system to perform the right separation with minimized exergy loses as shown below.

Traces of hydrocarbons are also extracted and concentrated to, again, promote subsequent operations of separation of dissolved salts. Although physico-chemical analysis only reveals the presence of hydrocarbons as trace we must not forget that the objective is to treat completely or $100 \%$ of groundwater. In general, the disadvantage attributed to the separation systems is to produce a concentrate that you cannot treat. In most methods of treating wastewater, sludge is produced, its analysis is not always easy and its disposal by landfill is not well regulated. The mass balance of the process is rarely done strictly and allows to forget the quantities of material. 
Our strategy allows to isolate the ammonia nitrogen to perform an advanced oxidation reaction converting, in ideal conditions of the stoichiometric ratio, the molecule into gaseous nitrogen and other harmless ions. This is an important advantage, because this reaction can be produced from the original wastewater because oxidants will first react with the other products present, before the ammonia nitrogen. Achieving a reaction in a stoichiometric ratio minimizes the exergy and therefore, the consumption of oxidants and the presence of by-products. The pilot tests have allowed, through a sequence of selective separations and optimized reactions to produce a nanopure water and completely destroy the ammonia nitrogen, responsible for the toxicity and ecotoxicity. The process does not generate sludge or concentrates. The produced water, of nanopure quality, can be used as process water for industry, rather than rejected in the river and then pumped out later by an industry and treated for use. We kept these waters under ambient conditions and light in transparent plastic bottles, closed from 2006 to 2010 . New physico-chemical, toxicity and ecotoxicity acute and chronic analysis performed in specialized laboratories according to Canadian standards and procedures, demonstrated the high stability of the water quality.

Another category of wastewater includes leachate of contaminated soil from which we want to extract heavy metals responsible for the contamination. Generally, they are acidic waters put in contact with the soil, in situ or in a reactor, and will dissolve heavy metals and carry out from the soil. Often this water is collected and processed to meet the discharge standards in the receiving environment. Our approach, according to a material balance, evaluates the effectiveness of our method based on heavy metals extracted and valorized. Indeed, we do not think that to decontaminate the soil, because of its market value, allows to transfer the contamination to a lower value site, such as burial in the bottom of a mine, encased in concrete. So we conducted laboratory and pilot tests have demonstrated the feasibility of the process. From these tests we revealed the behavior of some polymer materials whose performance depends on $\mathrm{pH}$. Another interesting aspect is the presence of salts such as $\mathrm{NaCl}$, which increases the efficiency of leaching. The proposed method allows large separations of heavy metals (greater than 95\%) and at the same time a small separation of monovalent salts like $\mathrm{NaCl}$ and good permeability to acids such as hydrochloric acid. These important properties and good resistance of new membranes to acidic conditions make this type of process very promising. In this case we can reuse the treated water to leach again, with the possibility to adjust the $\mathrm{pH}$ by concentrating. The fact that $\mathrm{H}+, \mathrm{Na}+$, $\mathrm{Cl}$ - can be transported with water in the pores, while heavy metals can not, is very important from the viewpoint of exergy balance because the motive force is much lower than if there were no salts or that the salts were separated by the process. Heavy metals contained in the other stream can be recovered by selective precipitation and/or electroplating. The net process balance uses no water, very little acid and salts which play the same role as a catalyst. The metals are recovered and recycled. No release is then issued and we have a clean process (clean technology) without discharge, consumption of chemical products and with low energy consumption.

Further tests were carried out successfully on various wastewater contaminated with hydrocarbons, heavy metals, trichlorethylene, etc.

\subsection{Waste water containing glycols}

Used in the industry as a coolant or antifreeze, or in airports, aqueous solutions of glycol are recovered and should be treated. Often, the bioreactors are used because of the good biodegradability of glycols, in other cases of authorization certificates are issued for 
discharging it with municipal wastewater. The advantage to reuse these glycols appeared in the 90s and processes such as distillation have been developed and installed sometimes on an industrial scale. However, the investment costs are high and these methods consume a great amount of energy. As with other applications users want absolutely recycled glycols but pure. What is remarkable with the aqueous solutions of glycol is their maximum efficiency depending on temperature and concentration. Pure glycols do not have antifreeze properties, but, when mixed with water the properties become very interesting. From a point of view of exergy, it will depend on concentration. In an initial step, preparing solutions with nanopure water and suitable additives for use, the wastewater collected as soon as possible after use can be treated, adjust with new additives and reused in the process. We designed a process that first removes suspended solids, then sterilizes water and purifies both the water and glycol. What makes this operation possible, is a judicious combination of pore size and affinity of the polymer to water and glycol. Osmotic pressure, as well as the boiling point of a glycol solution varies greatly with the concentration of glycol in the solution. The purified solution is then concentrated to the desired value, and the required additives are adjusted.

\subsection{Wastewater from the electronics industry}

In the electronics industry, we had the opportunity to design, fabricate and test a pilot process to treat wastewater from baths where are engraved printed circuits. This wastewater comes from purges of the baths necessary to adjust the concentration of copper by compensating the purge volume by an aqueous solution of hydrochloric acid $\mathrm{pH}=0$ with $\mathrm{H}_{2} \mathrm{O}_{2}$. When this is done daily or weekly the bath cannot function at the optimum, but in a range around the optimum point. Therefore a continuous treatment maintaining optimum conditions of the engraving bath is wished for. This is the type of treatment we designed by recycling the treated solution. We determined the characteristics of the treated solution corresponding to those of the optimum bath. The copper extracted corresponds to the copper taken off printed circuit boards during their passage through the engraving bath. the Development by manufacturers of membrane module resistant to these conditions of $\mathrm{pH}$ and aggressiveness of the solution enabled us to design this process. Another aspect arising from the exergy analysis is that we could modify the pore size to allow the system to perform the required separation. For example, if the optimum concentration of $\mathrm{Cu}$ is $12 \%$, as it increases to $15 \%$ for treatment, one must add the same flow rate for the solution at $10 \%$ of $\mathrm{Cu}$ to recover the optimal operating conditions followed by the extraction of copper.

The system must operate to meet these conditions (entry 15\%, output 10\%). Exergy analysis indicates that the motive force is depending on the concentration difference thus $15-10=5 \%$. Indeed, if we wanted to perform a separation of $15 \%$ to $0 \%$, the osmotic pressure would be too large and the current systems cannot perform this operation. The concentrate is then processed in a new process of electrofiltering that will allow, due to an electrical field as motive force, to transfer the excess copper in sulfuric acid solution which is the fluid of the plating process for the preparation of plates of printed circuits. Transferred copper is of excellent quality and there is no need for mineral extraction and processing. The resource is there and the quality is perfect.

Other cases were treated and in all these cases the exergy analysis guided the design. Adjusting of the pore size and the strengthening of affinities are the keys to the feasibility of these processes. An interesting and important case is the continuous growth of modern membrane engineering, whose basic aspects satisfy the requirements of process 
intensification. Membrane operations - with the intrinsic characteristics of efficiency, high selectivity and permeability for the transport of specific components, compatibility between different membrane operations in integrated systems, low energetic requirements, good stability under operating conditions and environment compatibility, easy scale-up, and large operational flexibility-represent an interesting answer for the rationalization of chemical and industrial productions (Drioli \& Giorno, 2010).

\section{Conclusion}

Today we can say that the theoretical means, models and technological tools are available to address the wastewater management in the context of sustainable development, starting by seeing it as a resource not to lose provided it is recovered in time.

Year 2010 recent environmental disasters are proof that we must reconsider how the industries that use water as process fluid or generate wastewater must proceed. A plant must be regarded as a system subjected to analysis of the exergy balance. For a long time in Canada and worldwide, the paper mills were established near rivers that carried the trunks of trees and supplied the mills, large consumers of water and energy. But a simple balance shows, and experience has shown it before, the timber itself contains more water than is needed for the process and unused parts have sufficient heating value to operate the plant and even provide energy to spare. Some plants have shown that circuit closure was possible and co-generation is commonplace, although there is still room for improvement.

The storage of hazardous materials shall be subject to security criteria and restricted to minimum volumes. In the past, and even now, the custom is to subtract of the costs of production the costs of wastewater treatment, considered to be prohibitive. Releases to the environment, moves to areas of lesser geopolitical regulations, hidden storage and number of irresponsible actions are part of the arsenal of industrial strategies. Sustainable development is increasingly entered into government policies. Indeed, it is extremely difficult, with a growing consumption (see the last sixty years), to turn the tide and act the opposite of traditional ways. Anthropic development has always been to make the most of resources with the least effort considering the nature as inexhaustible.

Those days are coming to an end: the deterioration of the ozone layer, the increase of $\mathrm{CO}_{2}$ in the atmosphere and its corollary that is the decrease of oxygen $\mathrm{O}_{2}$, oil resources, the reduction of forest areas, limiting cropland, dwindling water tables, melting glaciers are phenomena of global impact. It was not that long the earth was flat and the discovery of new worlds left to the imagination leisure to wander.

However, since the 70s, in some industrial countries, pollution of rivers, which had become veritable open sewers, has fallen sharply and even does not exist anymore. Two main reasons: the closure of many factories in the steel, textile, pulp and paper, primary processing; and the major effort to restore watercourses. Rising land prices, especially in urban areas, led to the rehabilitation of soils contaminated with hydrocarbons, buried waste or wastewater from old incinerators that produce toxic leachate continuously flowing into rivers or mingle to groundwater.

It has long been considered, even now, that wastewater is a necessary evil, it must be addressed without additional costs and if we can postpone their treatment may be that Mother Nature will do the job. Unfortunately it shows its limits today. The Gulf of Mexico, so large yesterday, appears today in 2010, as a large pool soiled with oil at the surface along the coast, in depth and even between two waters. Artificial lakes of wastewater from mines 
and oil sands alarm more and more in Canada. Salt-laden discharges following the desalination of sea water are visible from the air and affect the ecosystem. Realize that all wastewater must be treated as a new resource allows, in context, analyze its potential for valorization. Understand that the theoretical tools, mathematical models, computer simulations exist, know the rapid development of nanotechnology applied to this area as a means to act, will open the way for sustainable development without creating a new burden for generations future but by allowing them to expand these new intensive processes to maintain and improve their lifestyle.

Over one billion people lack access to clean water is a famous phrase a thousand times repeated by everyone and attributed to a report by the WHO or the UN in 1999. Since the world population increased from 6 to 7 billion and the number of people without access to drinking water has exceeded the 1.5 billion. For a long time the lack of potable water was associated with to a water shortage, which is the case in desert regions. It was also considered that the only way to access water was to dig wells.

One wonders now if the Nile can supply all of its residents. In fact, in most cases, water is available, but it is wastewater. The technologies exist to extract from the wastewater the vital resource, drinking water.

Energy, water, food and oxygen are our main resources and are not ready to be virtual. They represent the inevitable challenges of growth of humanity.

\section{References}

Agre, P., MacKinnon, P., (2003). Membrane Proteins: Structure, Function, and Assembly. Presented at the Nobel Symposium 126, Friibergh's Herrgård, Örsundsbro, Sweden, (August 23, 2003),

Allard, G., (1998). Application de l'osmose inverse à l'eau d'érable : Évaluation de membranes dans un prototype québécois. Technical Report, Ministère de l'Agriculture, des Pêcheries et de l'Alimentation du Québec. p.25-30 (1998),

Bird, R.D., Stewart, W.E., Lightfoot, E.N., (2002). Transport Phenomena, John Wiley, (2003),

Brodyansky, V.M., Sorin M., LeGoff, P., (1995). The Efficiency of Industrial Processes, Exergy Analysis and Optimization, Elsevier Science Publishers B.V., 487p, (1995),

Choi, J. H., Fukushi, K., Ng, H. Y., Yamamoto, K., (2006). Evaluation of a long-term operation of a submerged nanofiltration membrane bioreactor (NF MBR) for advanced wastewater treatment, Water Sci. \& Technol., 53(6), 131-136, (2006),

Drioli, E., Giorno, L., (2010). Comprehensive Membrane Science and Engineering. Elsevier Science Publishers , 2000 p., (2010) ISBN: 9780444532046

Gibbs, J. W., (1928). The Collected Works of J. Willard Gibbs. Longmans: New York, (1928),

Sourirajan, S. and Matsuura, T., (1985). Reverse Osmosis/Ultrafiltration Process Principles. National Research Council Canada, 113 p., (1985),

Le-Clech, P., Chen, V., Fane, A.G., (2006). Fouling in membrane bioreactors used for wastewater treatment - A review. Journal of Membrane Science, 284, 17-53, (2006),

Vrbka, L., Mucha, M., Minofar, B., Jungwirth, P., Brown, E. C., Tobias, D. J., (2004). Propensity of Soft Ions for the Air/Water Interface. Current Opinion in Interface and Colloid Science, 9, 67, (2004). 


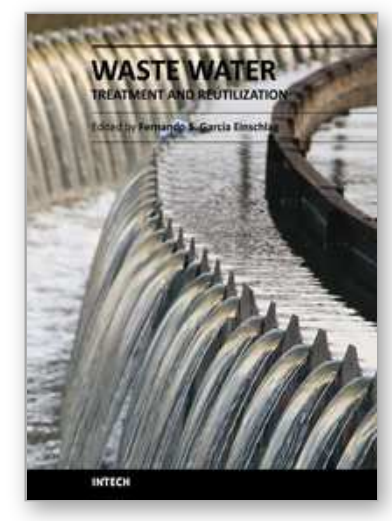

\author{
Waste Water - Treatment and Reutilization \\ Edited by Prof. Fernando Sebastiẽ $i n$ GarcÃa Einschlag
}

ISBN 978-953-307-249-4

Hard cover, 434 pages

Publisher InTech

Published online 01, April, 2011

Published in print edition April, 2011

The steady increase in industrialization, urbanization and enormous population growth are leading to production of huge quantities of wastewaters that may frequently cause environmental hazards. This makes waste water treatment and waste water reduction very important issues. The book offers a collection of studies and findings concerning waste water treatment, minimization and reuse.

\title{
How to reference
}

In order to correctly reference this scholarly work, feel free to copy and paste the following:

Rémi Ernest Lebrun (2011). Absolute Solution for Waste Water: Dynamic Nano Channels Processes, Waste Water - Treatment and Reutilization, Prof. Fernando SebastiÃ $i n$ GarcÃa Einschlag (Ed.), ISBN: 978-953-307249-4, InTech, Available from: http://www.intechopen.com/books/waste-water-treatment-andreutilization/absolute-solution-for-waste-water-dynamic-nano-channels-processes

\section{INTECH}

open science | open minds

\author{
InTech Europe \\ University Campus STeP Ri \\ Slavka Krautzeka 83/A \\ 51000 Rijeka, Croatia \\ Phone: +385 (51) 770447 \\ Fax: +385 (51) 686166 \\ www.intechopen.com
}

\author{
InTech China \\ Unit 405, Office Block, Hotel Equatorial Shanghai \\ No.65, Yan An Road (West), Shanghai, 200040, China \\ 中国上海市延安西路65号上海国际贵都大饭店办公楼405单元 \\ Phone: +86-21-62489820 \\ Fax: +86-21-62489821
}


(C) 2011 The Author(s). Licensee IntechOpen. This chapter is distributed under the terms of the Creative Commons Attribution-NonCommercialShareAlike-3.0 License, which permits use, distribution and reproduction for non-commercial purposes, provided the original is properly cited and derivative works building on this content are distributed under the same license. 